\title{
Resisting punitiveness 'in' and beyond Europe: The best and worst of times?
}

\author{
Richard Sparks \\ Professor of Criminology, Edinburgh Law School, the University of Edinburgh.
}

\begin{abstract}
It was the best of times, it was the worst of times, it was the age of wisdom, it was the age of foolishness, it was the epoch of belief, it was the epoch of incredulity, it was the season of Light, it was the season of Darkness, it was the spring of hope, it was the winter of despair, we had everything before us, we had nothing before us, we were all going direct to Heaven, we were

all going direct the other way - in short, the period was so far like the present period, that some of its noisiest authorities insisted on its being received, for good or for evil, in the superlative degree of comparison only.
\end{abstract}

Charles Dickens, A Tale of Two Cities (1859)

A long time ago, in 2009, my colleagues and I in the Scottish Centre for Crime and Justice Research invited Sonja Snacken to present our annual lecture. It was only the Centre's third annual lecture, and the first to be given by a scholar from outside the United Kingdom. It seemed quite natural to turn to Sonja at that moment, and this tells us a great deal about the esteem in which she is held in Scotland, as in so many other places. The talk she gave that evening in the calm magnificence of the Playfair Library in Edinburgh was entitled 'Resisting punitiveness in Europe'. The following year the full paper of that title came out in Theoretical Criminology (Snacken, 2010), followed in 2013 by the book co-edited with Els Dumortier in 2013 (Snacken \& Dumortier, 2013). I remember the occasion very clearly, like hearing a favourite piece of music played in concert by a full orchestra for the first time. I want to focus here on re-reading the 'Resisting punitiveness' paper today for several reasons. It seems to encapsulate a central set of concerns in Sonja's work. It drew attention - or perhaps better, it warned us about certain key dimensions in political culture that could have fateful effects on the uses of punishment in European societies and elsewhere. So much has 
happened since, and indeed is happening right now, that will have a bearing on the future of those questions, not least in Scotland and the rest of the United Kingdom. It is time to revisit the argument, with a wary but hopeful eye on what is to come.

I said at the outset that Sonja's talk in Edinburgh took place a long time ago. Today, in the long 'socially-distanced' summer of 2020, pretty much everything that happened prior to the last few months seems a long time ago. As we begin to emerge from our 'lockdown' - a prison metaphor, of course, but rarely interrogated carefully as such - we focus on many anxious questions about the future. What will what Lesley McAra calls 'the neo-

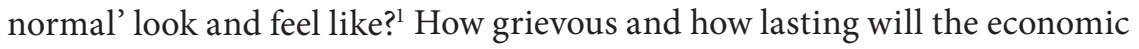
impacts of the pandemic be? How many people will lose their jobs? Will the theatres and restaurants ever reopen? So how different will the cities be? On the other hand, how can people retain the new connections, forms of intimacy and kinds of self-development that some of us have experienced during this time? If we have glimpsed the chance of a new, more responsible relationship with the natural world, for example, how do we retain this? If we have renewed our sense of the value of public service in respect of health and social care, how do we ensure that we embed these values more permanently? How much more ambitiously do we want our politics to speak to the general interest, therefore? What happens in the future in the realm of punishment may be a subsidiary question by comparison with some of these, but it stands alongside them nonetheless as a question about the future of politics, and the future of community.

Yet the suddenness and gravity of all these questions can serve to obscure all the other things that have also changed in the last ten years. Seen from here in Scotland, those years have been tumultuous ones. Following a bitterly divisive period in British politics, the United Kingdom has left the European Union. This poses a host of difficult questions about the nature of its future as a European nation-state. The UK of course remains a member of the Council of Europe and thus of its institutions (the European Convention and Court, the CPT and so on). Yet these may only become the next major battleground between those who want to defend Britain's commitments to values and standards that we identify as shared European ones, and those who wish to insist upon some form of Anglophone exceptionalism. As recently as 2014, Scottish voters had rejected the proposition of leaving the UK and becoming an independent nation-state. In 2020, after Brexit and with a widely held view amongst Scottish residents that the Scottish Government has handled

1 https://efi.ed.ac.uk/future-present-reflections-from-the-edinburgh-futures-institute/ 
the COVID-19 pandemic more calmly and consistently than the UK authorities, it is by no means so clear that that outcome would be repeated now. Meanwhile, in 2010 the word 'populism' was still a term mostly used by historians and social scientists, with perhaps a particular salience amongst criminologists concerned about penal politics. Today it has become central and unavoidable, and refers to an entire way of doing politics, not just to rhetorical moves in one field or another. At around the same time that Sonja Snacken was preparing her remarks on resisting punitiveness, Ian Loader and I were finishing our book Public Criminology? (Loader \& Sparks, 2010), which is centrally concerned with the problematic relations between knowledge and politics in the fields of crime control and punishment. What we conceived of at that time as a recurrent tension has instead become an open crisis and a site of struggle.

Ten years on from Sonja Snacken's important essay, it is not too much to say that we find ourselves at a critical juncture, certainly here, probably everywhere. In that piece and elsewhere (for example, van Zyl Smit \& Snacken, 2009) Snacken strongly associates European values at their best with penal moderation, social solidarity, the rule of law and the protection of Human Rights. I suspect those values are about to be severely tested by confluent crises. At the same time, many people are reaching for a sense of radical possibility, occasioned by the sense that mere reversion to former ways of doing things is not an option. These perspectives are what Loader and I have elsewhere called, following the great Welsh social critic Raymond Williams, 'resources of hope' (Loader \& Sparks, 2019; Williams, 1988). Does it make most sense to express the challenges of the present mainly in terms of defence (for example of cherished values in the face of a negative pole of possibility), as in 'resisting punitiveness'? Or, should we be seeking more boldly to redefine and reshape the field and its futures?

In 'Resisting punitiveness' Snacken sets out certain conditions that serve to restrain or exacerbate punitiveness. These primarily concern social policies (and the effects of more generous and inclusive welfare arrangements on promoting solidarities and moderating inequalities), political culture (and the restraints offered by democratic constitutionalism against populism and crude majoritarianism), and the specific role of adherence to Human Rights standards in forbidding the imposition of penal excesses. It is an important element of the paper's argument that 'punitiveness' is not a single dimension, exhaustively measured by the ubiquitous metric of rates of imprisonment per 100.000 members of a population. Rather, as the questions of rule of law and adherence to HR norms strongly suggest, it has crucial qualitative differences too. Thus, Snacken points out: 
[Punitiveness] refers in general to 'attitudes towards punishment', including, but not limited to: political discourse; primary criminalization by legislators; decisions taken by practitioners within the criminal justice system (police, prosecution, sentencing, implementation of sentences, release procedures, etc.); attitudes of revenge or forgiveness of victims of crime; or 'popular' attitudes towards punishment (so called 'public opinion').

(2010: 274)

For these reasons, Snacken strongly supports a nuanced, contextual approach to comparative penological inquiry that locates penal practices and institutions within the matrices provided by the differences of social policy, political culture and legal regulation that she outlines. Indeed, we might add, in the absence of some such perspective, empirically careful comparative study of differences is really neither necessary nor possible.

These seem to me to have been entirely necessary and important correctives to some of the more sweeping, generalizing perspectives that were especially current in the field at around the time of Snacken's article. The article sets out a prospectus for a much more feasible and in many respects more illuminating way of doing research on penal practices. It is a perspective that invites us to dig down into the ways in which these are constituted in situ in each of the places where they arise, and thereby to understand the mechanisms through which they take their fateful effects on people, the life chances, their communities and the surrounding divisions and conflicts of their societies. Moreover, to see penality as in these senses embattled is to return it to a more properly political frame of reference, where it rightly belongs. Snacken's account, with its emphasis on social policy and on legal and constitutional questions does exactly this. It reminds us that to resist punitiveness is also to engage in arguments about the inclusiveness or otherwise of our societies' modes of government; in arguments about the meanings and scope of citizenship; and in arguments about the place and power of Human Rights protections in regulating and restraining penal power. In all these respects it situates penality as an acute focus for questions about the legitimate uses of state powers, whether directly used or delegated to other parties. It reminds us that this is, to borrow E. P. Thompson famous phrase 'an arena of conflict' (Thompson, 1975: 262).

In my own forays in this area, I and my collaborators and students have very much tried to retain this awareness of difference and dispute. Whilst there certainly are globalizing and generic discourses in this field (of which Human Rights discourse, and its associated bodies of law and activism are perhaps the most important), much about the ways in which they translate 
into institutions and practices remains local, contingent and variable. For example, I tried to show that even something as apparently placeless as the use of techniques of risk assessment is never only a matter of technical calculation. Rather it also involves modes of representation of people and motives that figure in different penological contexts in very particular ways (Sparks, 2003: 170). Similarly, Dario Melossi, Máximo Sozzo and I have argued that whereas certain kinds of governmental discourse aim for maximum transportability (consider here the argument of efficiency in relation to the privatization of prisons, for example), they are only ever realized anywhere through a process of re-embedding in the local setting (Melossi et al., 2011). Some of the best current writing on these subjects takes this contextual understanding much further, whether in the form of querying the universal application of categories in the Global South (Sozzo, 2017), or in the more precise and historically sensitive discussion even of examples drawn from neighbouring countries (Brangan, 2019).

How do these observations inform the project of resisting punitiveness in the world of our immediate future, the one that follows the current emergencies? Like many of us in this field, Sonja Snacken is first and foremost a researcher, but one who has long-standing involvements in bringing her knowledge to bear on public purposes both within the worlds of Belgian penal policy and through international bodies such as the CPT. In the 'Resisting' paper it seems clear that the forms of knowledge that someone with these commitments brings to bear may involve, as in her own case, not only the skills of empirical inquiry, but also those of reflection upon legal and normative questions.

This seems important right now. We know for example that there are high risks of disease transmission in many prison systems around the world. We know that prison authorities have taken very different views on whether to release certain groups of prisoners (and into what other settings) in order to reduce those risks. We know that those who remain in prison are subject to very different conditions but that these can include periods of cellular confinement and isolation that look intensely problematic in terms of prevailing human rights standards. We know that people in prisons around the world experience many of the same deprivations as those outside, but sometimes for longer and in more acute forms (such as the ability to receive visits from family members and others). In some respects, therefore, the pandemic brings ${ }^{2}$ the circumstances of those undergoing punishment closer

2 See for example (for Europe): http://www.prisonobservatory.org/upload/17042020 European_prisons_during_covid19 \%233.pdf; (for Latin America) https://www.hrw. 
to those of us living outside the walls. The ubiquity of prison metaphors to describe aspects of everyday life - 'lockdown' again - makes this apparent. In other respects, incarceration under a state of emergency (like other kinds of deprivation and other forms of institutional living) may serve to magnify and intensify the disparities between people's fates. Moreover, the fear that some of the new forms of surveillance and control that authorities have introduced during the emergency (with at least conditional public support in many places) may outlast it, has special and worrying application to prisons, other places of confinement and other penal practices (such as electronic monitoring).

It seems perfectly clear, therefore, that a clear, comparative awareness of the qualitative aspects of penal regimes, as well as of their sheer scale, has rarely been more urgently required. It has never been more important to pursue the thorough empirical documentation of these realities. Equally, however it has never been more pressing to explore them in evaluative ways, in respect of their legitimacy, their compatibility with rule of law values, their implications for the human rights of their subjects. For all of those tasks the framework that Sonja Snacken sets out in 'Resisting punitiveness' is more specifically necessary now than ever.

It would be unfortunate, however, if we were to undertake these tasks only in a defensive spirit - the danger that the framing of the matter as 'resisting' something brings in train. There is an ambiguity here - in many respects characteristic of the field as a whole - between representing the rule of law as a kind of protective rampart, and the development of a human rights culture as the promotion of a new set of sensibilities (as in the closing lines of van Zyl Smit \& Snacken, 2009). As McAra also notes in the remarks cited above, the post-emergency neo-normal may include the discovery of new and more various solidarities. It may be one of those historical moments when the opportunity arises to promote forms of ordering and organization not premised on the othering of outcasts. It might turn out to be a high tidemark for certain forms of populism, and a moment when more reasonable and evidence-informed kinds of political speech can reassert themselves. It might be in our hands not merely to resist punitiveness but to outgrow it.

org/news/2020/04/02/latin-america-cut-prison-crowding-fight-covid-19; (for the United States) https://www.theverge.com/2020/3/7/21167807/coronavirus-prisonjail-health-outbreak-covid-19-flu-soap; (and globally) https://www.prison-insider. com/en/articles/coronavirus-la-fievre-des-prisons 


\section{References}

Brangan, L. (2019). Civilizing Imprisonment: The Limits of Scottish Penal Exceptionalism. British Journal of Criminology, 59(4), 780-799.

Dickens, C. (1859). A tale of two cities. London, UK: Chapman and Hall.

Loader, I., \& Sparks, R. (2010). Public Criminology? London: Routledge.

Loader, I., \& Sparks, R. (2019). Democratic experimentalism and the futures of crime control: resources of hope for demotic times. In P. Carlen \& L. Ayres França (Eds.), Justice Alternatives (pp. 105-20). London: Routledge.

Melossi, D., Sozzo, M. \& Sparks, R. (2011). Criminal Questions: Cultural Embeddedness and Diffusion. In D. Melossi, M. Sozzo \& R. Sparks (Eds.), Travels of the Criminal Question (pp. 65-94). Oxford: Hart.

Snacken, S. (2010). Resisting punitiveness in Europe?, Theoretical Criminology, 14(3), 273-292.

Snacken, S., \& Dumortier, E. (2013). Resisting Punitiveness in Europe?: Welfare, Human Rights and Democracy. London: Routledge.

Sozzo, M. (2017). 'A post-neoliberal turn?: variants of recent penal policy in Argentina', International Journal for Crime, Justice and Social Democracy, 6(1), 205-223.

Sparks, R. (2001). Degrees of estrangement: the cultural theory of risk and comparative penology. Theoretical Criminology, 5(2), 159-176.

Thompson, E. P. (1975). Whigs and Hunters: The Origin of the Black Act. London: Allen Lane.

Van Zyl Smit, D. \& Snacken, S. (2009). Principles of European Prison Law and Policy. Oxford: Oxford University Press.

Williams, R. (1988). Resources of Hope: Culture, Democracy, Socialism. London: Verso. 